\title{
BEETROOT JUICE - LEGAL DOPING FOR ATHLETES?
}

\author{
Katarzyna Kurowska ${ }^{A, B, D}$ \\ Siedlce University of Natural Sciences and Humanities, Faculty of Medical Sciences and Health Sciences, \\ Institute of Health Sciences, Poland \\ ORCID: 0000-0003-2892-5315
}

\section{Katarzyna Antosik ${ }^{B, D}$}

Siedlce University of Natural Sciences and Humanities, Faculty of Medical Sciences and Health Sciences, Institute of Health Sciences, Poland

ORCID: 0000-0001-7159-4254 | e-mail: katarzyna.antosik@uph.edu.pl

\section{Milena Kobylińska ${ }^{\mathrm{B}}$}

Siedlce University of Natural Sciences and Humanities, Faculty of Medical Sciences and Health Sciences, Institute of Health Sciences, Poland

ORCID: 0000-0002-3293-900X

\section{Agnieszka Decyk ${ }^{\mathrm{B}}$}

Siedlce University of Natural Sciences and Humanities, Faculty of Medical Sciences and Health Sciences, Institute of Health Sciences, Poland

ORCID: 0000-0002-2246-0249

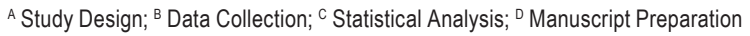

\begin{abstract}
Ahstract Nitric oxide (NO) is a physiologically important signaling molecule that promotes the expansion of blood vessels and thus facilitates the transport of oxygen $\left(\mathrm{O}_{2}\right)$ and energy substrates to the muscles. Research shows that nitric oxide (NO) also improves the effectiveness of mitochondrial respiration, which is manifested by reduced oxygen consumption during exercise. Until recently, it was thought that nitric oxide (NO) could only be formed as a result of the endogenous pathway of oxidative transformations L-arginine. Recent research results indicate, however, that an alternative to the endogenous pathway of nitric oxide (NO) formation may be the exogenous supply of inorganic nitrates $\left(\mathrm{NO}_{3}{ }^{-}\right)$with food.

The aim of the study was to review the current literature on the properties of beetroot juice as an important source of nitrates $\left(\mathrm{NO}_{3}{ }^{-}\right)$and its effectiveness in improving the exercise capacity of physically active people.

A systematic review of the research, published from 2005 to January 31, 2021, was made on the basis of searching bibliographic databases such as: PubMed, Elsevier and Web of Science. The following keywords were used: "beetroot", "beetroot juice", "nitrates", "nitrites", "nitric oxide", "supplementation", "ergogenic substances", "sports nutrition".

Although there are conflicting data, it appears that beetroot juice supply may be a cheap, natural, and promising nutritional strategy for improving sports performance in both endurance and intermittent high intensity (start-stop) exercise. More detailed studies are analyzing the effect of dietary nitrate $\left(\mathrm{NO}_{3}{ }^{-}\right)$supply in anaerobic exercise - especially in high-volume resistance training - are needed. It is also emphasized that further research is needed to elucidate the effects of specific factors on the variability of ergogenic effects after beetroot juice consumption, which may be of the greatest importance in terms of the effectiveness of this nutritional intervention.
\end{abstract}

Key Worlls beetroot juice, ergogenic compounds, sports, nitrates, nitrites 


\section{Introduction}

The introduction of novel training stimuli allows athletes to achieve optimal performance during exercise (Campbell, Winiewski, 2017). It is increasingly observed that adaptations initiated by physical activity can be enhanced by appropriately selected nutritional strategies, which include guidelines for the type, quantity and timing of meals or fluids intake, and in specific situations, the use of supplements and sports nutrition (Jeukendrup, 2017). The aim of these strategies is, among other things, to cover individual energy needs taking into account the training periodization, to maintain carbohydrate availability especially during endurance exercise, to increase post-workout glycogen resynthesis, to regulate muscle protein synthesis and body water management (Belval et al., 2019; Thomas, Erdman, Burke, 2016; Vitale, Gatzin, 2019).

According to the American College of Sports (ACSM), Academy of Nutrition and Dietetics (AND), and Dietitians of Canada (DC), proper adjustment of nutrient supply in relation to the exercise performed is essential for improved athletic performance (Thomas et al., 2016). Consequently, much of the current research, focuses on the effects of the intake of specific foods, including the use of isolated food ingredients and dietary supplements to improve not only health but also exercise capacity (Clements, Lee, Bloomer, 2014).

Based on current research, the Australian Institute of Sport (AIS) has classified food ingredients and dietary supplements for athletes into four groups while determining whether they are safe, legal, and effective in improving excercise performance. In category A, which includes food ingredients and dietary supplements with proven effects on improving exercise capacity, the AIS included beetroot juice (Australian Institute of Sport [AIS], 2020; Maughan et al., 2018). Undoubtedly, its use has gained great popularity among physically active people in recent years and appears to be a cheap, natural and promising nutritional intervention for enhancing physical performance. The ergogenic effect induced by beetroot juice consumption is related to its high content of inorganic nitrates $\left(\mathrm{NO}_{3}{ }^{-}\right)$, converted in the body to nitric oxide (NO), which is a physiologically important signaling molecule that dilates blood vessels and thus can increase blood flow to muscles, facilitating oxygen $\left(\mathrm{O}_{2}\right)$ transport. In addition, studies have shown that nitric oxide (NO) improves the efficiency of mitochondrial respiration, so that the oxygen cost of exercise is significantly reduced (Dominguez et al., 2017).

\section{Objective of the work}

The aim of the study was to review the current literature on the properties of beetroot juice as an important source of nitrates $\left(\mathrm{NO}_{3}{ }^{-}\right)$and its effectiveness in improving the exercise capacity of physically active people.

\section{Methodology}

A systematic review of studies published from January 1, 2005 to January 31, 2021 was performed. For this purpose, bibliographic databases such as PubMed, Elsevier and Web of Science were searched. Keywords were used: "beetroot", "beetroot juice", "nitrates", "nitrites", "nitric oxide", "supplementation", "ergogenic substances", "sports nutrition". The information considered relevant was included in this review.

\section{The mechanism of the nitric oxide (NO) formation}

Beetroot juice is used as an ergogenic substance due to its high content of inorganic nitrate $\left(\mathrm{NO}_{3}\right)$, which is the precursor for nitric oxide (NO) in the human body (Lundberg, Weitzberg, Gladwin, 2008). Until recently, it was 
thought that nitric oxide (NO) could only be formed by the endogenous pathway of oxidation of L-arginine, catalyzed by several isoforms of nitric oxide synthase (NOS), in the presence of molecular oxygen and such chemical reaction cofactors as NADPH, FAD, $\mathrm{BH}_{4}$ (Ignarro, Fukuto, Griscavage, Rogers, Byrns, 1993). However, recent findings indicate that an alternative to the endogenous pathway of nitric oxide (NO) formation, may be the exogenous supply of inorganic nitrate $\left(\mathrm{NO}_{3}{ }^{-}\right)$with food. This means that large amounts of nitrate $\left(\mathrm{NO}_{3}{ }^{-}\right)$present in beetroot juice are able to increase nitric oxide (NO) levels in the human body (Bailey et al., 2009; DeMartino, Kim-Shapiro, Patel, Gladwin, 2019).

Other food products rich in inorganic nitrates $\left(\mathrm{NO}_{3}{ }^{-}\right)$include, among others green leafy vegetables, such as savoy cabbage, Chinese cabbage, endive, fennel, lettuce, spinach, rucoli, a well as vegetable and fruit juices, e.g. carrot juice or pomegranate juice, and drinking water. It is estimated that the content of nitrates in the aforementioned vegetables is in the case of with cabbage, Chinese cabbage, fennel and endive drom 500-2,500 mg $(9-40 \mathrm{mmol}) / 1 \mathrm{~kg}$ of fresh vegetables, while in the case of lettuce, spinach, rucoli and beetroot (including beetroot juice) $-2,500 \mathrm{mg}(40 \mathrm{mmol}) / 1 \mathrm{~kg}$ of fresh vegetables, respectively. It should be noted that the content of nitrates in plant product varies depending on their type and largely depends on environmental factors such as climate, soil conditions or the time elapsed from harvesting (Hord, Tang, Bryan, 2009; Santamaria, 2005).

It should also be mentioned that the source of nitrates in the diet may be meat products in which nitrates are used as a preservative (Murphy, Eliot, Heuertz, Weiss, 2012).

The average food intake of nitrates among adults in the United States, Europe and Australia is $60-120 \mathrm{mg} / \mathrm{day}$ (1-2 mmol/day). Based on the data obtained, it is estimated that vegetables are the main source of this compound in the diet of adults (80-85\%). Researchers also suggest that vegetarians and people who follow nutritional models such as the DASH (Dietary Approaches to Stop Hypertension) diet are likely to achieve higher intakes of nitrates with food (AIS, 2020; Clements et al., 2014).

In the initiation of the exogenous pathway of "nitrate - nitrite - NO" metabolism, an important role is played by the oral microbiome, specifically, commensal, anaerobic bacteria residing in crypts distributed on the surface of the tongue, which degrade $25 \%$ of the nitrate $\left(\mathrm{NO}_{3}^{-}\right)$ingested with food to nitrite $\left(\mathrm{NO}_{2}^{-}\right)$via nitrate reductase enzymes (Qu, Wu, Pang, Jin, Qin, Wang, 2016). Subsequently, part of the nitrite $\left(\mathrm{NO}_{2}^{-}\right)$is converted to nitric oxide (NO) in the stomach by a non-enzymatic mechanism that is dependent on low pH (Lundberg, Carlström, Larsen, Weitzberg, 2011), and the remainder is absorbed from the small intestine, from which it enters the systemic circulation, where it can be reduced to nitric oxide (NO) in the blood or in other body tissues, with the involvement of deoxyhemoglobin, among others, under conditions of low oxygen availability (hypoxia) (Lundberg et al, 2008). Importantly, researchers have observed that skeletal muscle probably contains the largest storage of nitrate $\left(\mathrm{NO}_{3}{ }^{-}\right)$in the body. Nitrate $\left(\mathrm{NO}_{3}{ }^{-}\right)$stored in muscle tissue, under hypoxic and acidic conditions resulting from the accumulation of lactic acid accumulated during exercise, is used to produce nitrite $\left(\mathrm{NO}_{2}{ }^{-}\right)$and subsequently form nitric oxide (NO), which may explain the potential benefits for athletes in terms of improved exercise capacity (Piknova et al., 2015; Piknova, Park, Kwan, Lam, Schechter, 2016).

Nitric oxide (NO) is a physiologically relevant signaling molecule that has important hemodynamic and metabolic functions (Dominguez et al., 2018; Ferguson et al., 2013; Jones et al., 2021; Larsen, Weitzberg, Lundberg, Eklbom, 2007). Studies have shown that it plays an essential role in the regulation of blood flow and, more specifically, favors vasodilation (Furchgott, Jothianandan, 1991), resulting in increased transport of oxygen and, among others, energy 
substrates i.e. glucose and lipids to the muscles, thus supporting exercise performance and post-exercise recovery speed (Puype, Ramaekers, Thienen, Deldicque, Hespel, 2015).

Furthermore, nitric oxide (NO) has been found to induce gene expression, enhancing biogenesis and mitochondrial efficiency, through a cGMP - dependent mechanism, thus improving mitochondrial efficiency in skeletal muscle (Dejam, Hunter, Schechter, Gladwin, 2004; Pinna et al., 2014). These effects benefit from increased efficiency of oxidative metabolism, manifested by reduced oxygen consumption during exercise, or more productive phosphocreatine resynthesis (Ahluwalia et. al., 2016; Allen et al., 2010; Larsen et al., 2007; Larsen, Schiffer, Weitzberg, Lundberg, 2012).

The efficiency of mitochondrial oxidative phosphorylation is classically measured as the amount of oxygen consumed per amount of ATP produced, referred to as the P/O ratio (Hinkle, 2005). The research results indicate an improvement in the mitochondrial $\mathrm{P} / \mathrm{O}$ ratio as a result of the exogenous supply of nitrates $\left(\mathrm{NO}_{3}{ }^{-}\right)$. There are several possible interactions between nitrate $\left(\mathrm{NO}_{3}{ }^{-}\right)$, nitrite $\left(\mathrm{NO}_{2}{ }^{-}\right)$, nitric oxide $(\mathrm{NO})$, and the mitochondrion. Perhaps the best characterized effect of $\mathrm{NO}$ is its binding to cytochrome $\mathrm{C}$ oxidase (COX) and the terminal electron acceptor in the electron transport system (ETS) (Brown, Cooper, 1994). Research results indicate that nitrates mechanically contribute to $\left(\mathrm{NO}_{3}{ }^{-}\right)$reduction in the expression of ATP/ADP translocator, a protein involved in proton conduction, which has a profound impact on the basic function of mitochodndria in skeletal muscle (Larsen et al., 2011).

\section{The importance of beetroot juice in the nutrition of people with increased physical activity}

The results of research concerning the influence of nitrates $\left(\mathrm{NO}_{3}{ }^{-}\right)$as a precursor of nitric oxide (NO) and the resulting benefits for the human organism have led scientists to analyze the influence of an increased supply of nitrates $\left(\mathrm{NO}_{3}{ }^{-}\right.$) together with food, i.e. beetroot juice on the performance of athletes of various sports (Larsen et al., 2007). In addition, the enormous workload of exercise, during which athletes often balance between training hard enough and achieving their goals and at the same time avoiding the risk of injury, has given rise to the need to look for new ways, including nutritional, that could protect the athlete's body. The aim of these interventions would be, among other things, to reduce the risk of delayed onset muscle soreness syndrome (DOMS), which potentially increases the risk of injury (Flores, Gomez, Estrada-Catrillion, Smitaman, Pathria, 2018), or to improve post-workout recovery, allowing athletes to compete at the highest possible level of performance.

The first study conducted in this area to verify whether nitrate $\left(\mathrm{NO}_{3}{ }^{-}\right)$has any effect on metabolic parameters during exercise was conducted by Larsen et al. (2007). The authors, in a randomized double-blind crossover study, examined the effects of a three-day supply of nitrate $\left(\mathrm{NO}_{3}{ }^{-}\right)$in the form of sodium nitrate, at a dose of $0.1 \mathrm{mmol} /$ $\mathrm{kg}$ b.w./day, on physiological and metabolic parameters of male athletes. Based on the results obtained after tests performed on a cycle ergometer at submaximal intensity, they showed that the aerobic cost of exercise decreased after sodium nitrate supply compared to the placebo group. Furthermore, in this study, there was no increase in lactic acid concentration in muscle tissue, which would indicate more efficient energy production during exercise.

Given the results of the above study, Bailey et al. (2009) set out to determine if similar effects could be achieved through the administration of nitrate $\left(\mathrm{NO}_{3}{ }^{-}\right)$rich beetroot juice. This is an important question given that sodium nitrate is a pharmaceutical, whereas beetoot juice is a natural food product that can easily be included as part of a balanced diet. The researchers therefore hypothesized that beetroot juice supply is able to reduce the aerobic cost of moderate-intensity exercise and increase exercise tolerance during high-intensity exercise. An additional goal was to determine the effects of beetroot juice, and thus nitrate $\left(\mathrm{NO}_{3}{ }^{-}\right)$, on plasma, blood pressure, 
and muscle oxygenation in athletes. In a crossover double-blind study, the athletes were given beetroot juice for six days at $500 \mathrm{ml} /$ day, equivalent to $5.5 \mathrm{mmol} / \mathrm{NO}_{3}{ }^{-}$, and in addition, the athletes were asked to refrain from consuming other products containing nitrate $\left(\mathrm{NO}_{3}{ }^{-}\right)$, according to a list provided. On the last three days of the experiment, the athletes were subjected to exercise testing. Based on the results, the supply of nitrate $\left(\mathrm{NO}_{3}{ }^{-}\right)$along with beetroot juice resulted in an increase in plasma nitrite $\left(\mathrm{NO}_{2}^{-}\right)$concentration, a decrease in systolic blood pressure, as well as an improvement in muscle oxygenation indices and a decrease in $\mathrm{VO}_{2 \max }$. The authors of this study suggested that increased dietary nitrate $\left(\mathrm{NO}_{3}{ }^{-}\right)$intake could potentially increase exercise tolerance during prolonged endurance exercise.

A study by Rokkendal - Lausch et al. (2019) confirmed the beneficial effects of high nitrate intake - $12.4 \mathrm{mmol}$ $\mathrm{NO}_{3}{ }^{-}$along with beetroot juice among trained cyclists. In a randomized, crossover, double-blinded trial, it was shown to improve the athletes' performance during $10 \mathrm{~km}$ of cycling. Similar results were obtained by researchers at Maringa State University (de Castro, de Assis, Figueiredo, Machado, 2019), who showed that a three-day supply of $42 \mathrm{ml}\left(8.4 \mathrm{mmol} \mathrm{NO}_{3}{ }^{-}\right)$of beetroot juice among recreationally trained long-distance runners was able to effectively increase the average speed and final time during the athletes' $10 \mathrm{~km}$ run.

On the other hand, in a systematic review of studies, Dominguez et al. (2017) showed that nitrate $\left(\mathrm{NO}_{3}{ }^{-}\right)$ supply, in the form of beetroot juice, can have ergogenic effects on cardiorespiratory fitness, and furthermore increase energy production at the same $\mathrm{VO}_{2 \max }$ values, in trained athletes under normoxia and hypoxia. This is important, due to the fact that such a nutritional strategy could be a factor in potentially increasing energy efficiency, in athletes training for endurance sports. Moreover, the researchers concluded on the basis of the obtained data that beetroot juice consumption should be started about 90 minutes before exercise, because after this time the maximum increase in plasma nitrite $\left(\mathrm{NO}_{2}^{-}\right)$concentration is observed. Most of the studies analyzed by the authors indicated that the optimal supply of nitrates $\left(\mathrm{NO}_{3}{ }^{-}\right)$with beetroot juice was between $6-8 \mathrm{mmol} \mathrm{NO}_{3}^{-}$, although as it turned out, this is not a fully justified dose in such sports disciplines as kayaking or rowing. Based on the data obtained, the researchers suggested that nitrate supply should be higher when performing exercise involving the upper extremities. In addition, this review of studies confirmed that a chronic supply (up to 15 days) of beetroot juice may be equally effective in improving cardiorespiratory fitness as a single dose.

Another review of studies was also published in 2020 that proved the efficacy of nitrate supply with diet, and although a small increase of only $3 \%$ in exercise performance was shown, in the context of athletic participation, this small increase can significantly affect athletes' performance and determine victory (Senefeld et al., 2020). Indeed, research indicates that even a $0.6 \%$ improvement in performance can change the state of sports competition (Paton, Hopkins, 2006). The cited study noted the lack of research among women, which may have contributed to the authors' results of a lack of significant benefits regarding increased physical performance. The same lack of effect was noted among professional athletes and among athletes performing prolonged efforts (>15 minutes) of lower intensity. The optimal nitrate supply proposed by the authors of this study was between 5 and $25 \mathrm{mmol}$ $\mathrm{NO}_{3}{ }^{-}$, taken 2-3.5 hours before training (in none of the analyzed studies was an ergogenic effect obtained at values below $5 \mathrm{mmol} \mathrm{NO}_{3}^{-}$) (Senefeld et al., 2020).

Peacock et al. (2012) in their studies, the aim of which was to analyze the impact of the consumption of nitrates $\left(\mathrm{NO}_{3}{ }^{-}\right)$with a diet on the improvement oh the efficiency of cross - country skiers during 5 and $10 \mathrm{~km}$ run, also showed that the short - term supply of nitrates $\left(\mathrm{NO}_{3}{ }^{-}\right)$in the diet may not be an effective strategy for reducing 
the aerobic cost of exercise during submaximal exercise, and it does not increase the performance of endurance exercise among highly trained endurance athletes.

Similar results were obtained by Cermak Res, Stinkens, Lundberg, Gibala, van Loon et al. (2012) who showed no improvement in exercise capacity among traing cyclist after the supply of nitrates $\left(\mathrm{NO}_{3}^{-}\right)$wuth beetroot juice at a dose od $8.7 \mathrm{mmol}$ compared to group of placebo.

In turn, researchers from a research center in Spain did not confirm improvements in such analyzed variables as cardioventilation variables, $\mathrm{VO}_{2 \max }$ level, economy of exercise performed, or effects on time trial among male triathletes, during a bicycle ergometer test (Garnacho-Castano et al., 2018).

There are several theories due to which both the degree of training and the intensity of exercise may affect the ergogenic effect of the use nitrates $\left(\mathrm{NO}_{3}{ }^{-}\right)$with beetroot juice (Wilkerson et al., 2012). It has been shown that in the case of highly trained athletes, the exogenous "nitrate - nitrite - NO" pathway may be less important due to the high activity od the endogenous L-arginine oxidation patwahy (NOS) (McConell et al., 2007). Moreover, the response to the standard dose of nitrate $\left(\mathrm{NO}_{3}^{-}\right)$along with beetroot juice may be less effective in highly trained athletes due to the higher starting nitrite $\left(\mathrm{NO}_{2}^{-}\right)$level in the blood plasma, compared to people who lead a sedentary lifestyle (Poveda et al., 1997). It should also be mentioned that nitrites $\left(\mathrm{NO}_{2}{ }^{-}\right)$are reduced to nitric oxide (NO) under hypoxic conditions, while due to the greater capliiarity of skeletal muscles in highly trained athletes, muscle tissue hypoperfusion may be minimized during physical exertion, thus leading to a reduction in demand on the production of nitric oxide (NO) by the reduction of nitrite $\left(\mathrm{NO}_{2}{ }^{-}\right)$. The above mechanism also explains the reduced effectiveness of nitrate $\left(\mathrm{NO}_{3}{ }^{-}\right)$in low - intensity endurance exercise, due to the fact that highly trained athletes who performed endurance traning usually work with optimal blood flow and $\mathrm{O}_{2}$ distribution levels (Jensen, Bangsbo, Hellsten, 2004).

Due to the above data, Wilkerson et al. (2012) proposed that, based on the $\mathrm{NO}_{2}{ }^{-}$response in the blood plasma, athletes should be divided into two groups - "responders" and "non-responders" to the supply of nitrates $\left(\mathrm{NO}_{3}{ }^{-}\right)$ along with beet juice. It should be emphasized that factors such as the dose of nitrates $\left(\mathrm{NO}_{3}{ }^{-}\right)$with beetroot juice, the intensity of exercise or the individual response of the body are important factors that may affect the effectiveness of a nutritional intervention, which is the supply of beetroot juice in relation to improve exercise capacity. It has been suggested that an increased dose may be required among elite athletes to obtain similar performance enhancement benefits as for intermediate level athletes (Garnacho-Castano et al., 2018).

Based on the research conducted by Logan - Sprenger, Logan (2016), it was shown that women consuming higher amounts of nitrates $\left(\mathrm{NO}_{3}^{-}\right)$with the diet per $1 \mathrm{~kg}$ of body weight $\left(2.4 \mathrm{mg} \mathrm{NO}_{3}{ }^{-} / \mathrm{kg} \mathrm{b}\right.$.w.) showed an increased response on the supply of nitrates $\left(\mathrm{NO}_{3}{ }^{-}\right)$with beetroot juice, compared to men (1.3 $\mathrm{mg} \mathrm{NO}_{3}{ }^{-} / \mathrm{kg} \mathrm{b.w}$.). The results of the research indicate that athletes are characterized by a higher daily intake of nitrates $\left(\mathrm{NO}_{3}{ }^{-}\right)$with their diet compared to the general population. Therefore, the researchers point out that the elevated starting values of nitrite $\left(\mathrm{NO}_{2}{ }^{-}\right)$in the blood plasma of highly trained individuals may be partially the result of consuming more foods that are naturally rich in nitrates $\left(\mathrm{NO}_{3}^{-}\right)$.

There is also scientific evidence that contradicts the claim that nitrate $\left(\mathrm{NO}_{3}{ }^{-}\right)$supply along with beetroot juice would bring benefits in terms of improving sports performance even among less trained. Such conclusions were reached by Hurst, Saunders, Coleman (2020), who in their study showed no difference between the time running performance over a distance of $5 \mathrm{~km}$ in recreationally trained runners taking nitrate-rich beetroot juice $(70 \mathrm{ml}$, $4.1 \mathrm{mmol} \mathrm{NO}_{3}^{-}$) compared with the placebo group. 
Currently, an area of interest for researchers is the use of nitrate $\left(\mathrm{NO}_{3}{ }^{-}\right)$rich beetroot juice in team sports characterized by periods of high intensity activity interspersed with periods of relative recovery (start-stop exercise). Thompson, Vanhatalo, Jell, Fulford (2016) undertook to investigate the effect of nitrate $\left(\mathrm{NO}_{3}{ }^{-}\right)$on the performance of this type of exercise using the Yo-Yo Intermittent Recovery level 1 test. In a randomised, crossover, double-blind study, a control group of recreationally trained athletes received, for five days, $70 \mathrm{ml}$ of concentrated beetroot juice $\left(6.4 \mathrm{mmol} \mathrm{NO}_{3}{ }^{-}\right)$, while a placebo group received $70 \mathrm{ml}$ of nitrate $\left(\mathrm{NO}_{3}{ }^{-}\right)$depleted beetroot juice, also. Based on the data obtained, the supply of $\mathrm{NO}_{3}{ }^{-}$rich beetroot juice improved maximum performance in sprint and high-intensity interval running among athletes. The authors of the study suggested that this effect may translate into performance not only in individual sports but also in team sports.

Similar conclusions were reached by researchers in the Netherlands, who showed that a supply of beetroot juice improved athletes' performance during the Yo-YolR1, and also lowered the heart rate of athletes in the control group compared to the placebo group (Nyakayiru et al., 2017). The researchers inferred that a six-day supply of $140 \mathrm{ml}\left(12.9 \mathrm{mmol} \mathrm{NO}_{3}{ }^{-}\right)$of beetroot juice was effective in improving the performance of intermittent highintensity exercise, including high-intensity running and sprinting series, in trained soccer players. It should be noted that the nature of this type of exercise is dependent on the contribution of type II muscle fibers. This issue has been addressed by researchers from the United States and Sweden. Ferguson et al. (2013) using an animal model in their study evaluated the effect of dietary nitrate supply on blood flow during submaximal exercise. The authors observed that the increase in blood flow and vascular conductance in the limbs involved in the exercise was increased primarily in fast twitch muscle fibers. On the other hand, Hernandez et al. (2012) demonstrated that dietary nitrate supply influences increased calcium $\left(\mathrm{Ca}^{2+}\right)$ reuptake from the endoplasmic reticulum, in type II muscle fibers in mice, which translates into increased muscle contraction force, and thus may indicate an ergogenic effect of nitrate $\left(\mathrm{NO}_{3}{ }^{-}\right)$for efforts involving the above type of muscle fibers.

Daab, Bouzid, Lajri, Bouchiba, Saafi, Rebai (2020) conducted an experiment in which the effects of beetroot juice consumption on the kinetics of fitness recovery, levels of markers of muscle damage and perceived muscle soreness were analyzed among athletes after a simulated soccer game. Reduced levels of creatine kinase (CK) and lactate dehydrogenase (LDH), indicative of muscle damage, were noted. In addition, they also showed reduced acute phase protein - CRP levels and no onset of delayed onset muscle soreness syndrome (DOMS) among football players who took nitrate-rich beetroot juice $\left(\mathrm{NO}_{3}{ }^{-}\right)$, compared to the placebo group. A review of studies by RojasValverde, Montoya-Rodriquez, Azofeifa-Mora, Sanchez-Urena (2020) also confirmed the benefits of beetroot juice intake, applied both in a single dose (250 $\mathrm{ml}$ to $500 \mathrm{ml}$ ) 2.5-3 hours before exercise and taken 3-6 days before the exercise test, in the amount of $70 \mathrm{ml}$. Based on the results, an improvement in the athletes' resistance to exhaustion during repeated sprints was observed, which manifested itself in an increased number of running repetitions. Other conclusions were reached by researchers from Spain (Lopez - Samanes, Parra, Moreno-Perez, Courel-Ibanez, 2020), who analyzed the effect of beetroot juice supply on the improvement of neuromuscular efficiency, among basketball players. The authors in their experiment did not demonstrate the effectiveness of this type of nutritional intervention. Similar results were obtained by Fernandez-Elias et al. (2020), who showed that a single $70 \mathrm{ml}$ supply of beetroot juice appears to be an ergogenic agent of little value for improving the performance of physical exercise performed by professional tennis players.

The cross-section of research on the effects of beetroot juice intake on athletes of endurance and speed sports is quite wide, while there are limited data on the evaluation of ergogenic potential in resistance training i.e. 
weightlifting. A meta-analysis conducted by San Juan, Dominguez, Lago-Rodriguez, Montoya, Tan, Bailey (2020), on nitrate $\left(\mathrm{NO}_{3}\right)$ supply along with beetroot juice on improving muscle strength, contraction velocity and muscular endurance during weightlifting, showed that beetroot juice supply may be a promising nutritional intervention in improving contraction velocity and the ability of athletes to perform more repetitions during weightlifting, however, it was emphasized that further research is needed in this area.

Also published in 2020 were the results of a randomized double-blind study that evaluated the effects of beetroot juice supply on muscular endurance and concentric movement velocity during resistance training, specifically during exercises performed by athletes in the form of back squat and bench press (Ranchal-Sanchez, Diaz-Bernier, De La Florida-Villagran, CLlorente-Cantarero, Campos-Perez, Jurado-Castro, 2020). The data obtained confirmed the effectiveness of the nutritional strategy used by increasing the maximum number of repetitions during the squat, but these benefits were not observed when the athletes performed the test in the form of bench press.

\section{Nitrates $\left(\mathrm{NO}_{3}{ }^{-}\right)$from beetroot juice vs supplementation with sodium nitrate (NIT/NaNOO$\left.{ }_{3}^{-}\right)$}

Undoubtedly, a very important issue is also the assessment of the effectiveness of the use of an increased supply of nitrates $\left(\mathrm{NO}_{3}{ }^{-}\right)$with beetroot juice compared to supplementation with sodium nitrate $\left(\mathrm{NIT/NaNO}{ }^{-}\right)$in terms of improving exercise capacity.

Flueck, Bogdanova, Mettler, Perret (2016) conducted a study to compare the effects of sodium nitrate (NIT) and nitrate $\left(\mathrm{NO}_{3}{ }^{-}\right)$ingested with beetroot juice fo oxygen $\left(\mathrm{O}_{2}\right)$ consumption in male athletes during moderate to high intensity exercise. Twelve men took part in the study, who were subjected to an exercise test on a bicycle ergometer for seven days and received various doses of nitrates $\left(\mathrm{NO}_{3}{ }^{-}\right)$in the form of concentrated beetroot juice or sodium nitrate (NIT) dissolved in pure water (3, 6, 12 mmol NO3-). The concentrations of nitrates $\left(\mathrm{NO}_{3}{ }^{-}\right)$and nitrites $\left(\mathrm{NO}_{2}{ }^{-}\right)$in the plasma were measured before, three hours after consumption and after the exercise test. Oxygen $\left(\mathrm{O}_{2}\right)$ consumption of the moderate - intensity exercise test did not differ significantly between exercise over the seven days. However, with high - intensity exercise, oxygen $\left(\mathrm{O}_{2}\right)$ consumption was approximately $4 \%$ lower when 6 mmol nitrate $\left(\mathrm{NO}_{3}{ }^{-}\right)$was consumed in beetroot juice compared to the same dose of sodium nitrate (NIT). The authors of the study concluded that beetroot juice can reduce oxygen consumption to a greater extent than sodium nitrate (NIT), and thus more effectively improve the exercise capacity of physically active athletes.

In turn, Clifford, Howaston, West, Stevenson (2017) conducted a study to compare the effects of nitrate $\left(\mathrm{NO}_{3}{ }^{-}\right)$ consumed with beetroot juice and a drink containing only sodium nitrate $\left(\mathrm{NIT} \mathrm{NaNO}_{3}{ }^{-}\right)$on exercise-induced muscle injury rates (EIMD). Thirty recreational men were divided into three groups, each of which received a different type of supplementation (concentrated beetroot juice, sodium nitrate or isocaloric placebo) immediately after the exercise test and 24 and 48 hours after. To assess muscle damage, maximal isometric voluntary contractions (MIVC), pressure pain threshold (PPT), creatine kinase (CK), and high-sensitivity-reactive protein C (hs-CRP) were measured immediately after exercise, 24, 48 and 72 hours after exercise test. Based on the obtained data, the authors of the study suggested that the supply of nitrates $\left(\mathrm{NO}_{3}{ }^{-}\right)$with beetroot juice is more effective than sodium nitrate (NIT) in relieving EIMD-related muscle pain, and any analgesic effects are most likely related to the content of beetroot juice. phytonutrients other than nitrates $\left(\mathrm{NO}_{3}{ }^{-}\right)$or due to their interaction. 


\section{Toxicity of nitpates $\left(\mathrm{NO}_{3}^{-}\right)$and nitrites $\left(\mathrm{NO}_{2}^{-}\right)$}

Based on the results of research carried out in previous years, it was found that nitrates $\left(\mathrm{NO}_{3}{ }^{-}\right)$and nitrites $\left(\mathrm{NO}_{2}^{-}\right)$have a negative effect on the human body, contributing to the formation of N-nitroso compounds (NOCs) potentially carcinogenic compounds (Mirvish, 1995; Tannenbaum, Sinskey, Weisman, Bishop, 1974).

Studies on the effect of beetroot juice consumption on the production of N-nitroso compounds (NOCs), and thus analyzing its consumption in relation to the risk of cancer, are limited. In a randomized controlled trial, the aim of which was to analyze the endogenous formation of $\mathrm{N}$-nitroso compounds after consumption of beetroot juice and the effect of vitamin $\mathrm{C}$ supplementation on the excretion of the above-mentioned. compounds with urine, it was shown that in 29 healthy adults, recreationally active, consumption of concentrated beetroot juice in a dose of $70 \mathrm{ml}\left(400 \mathrm{mg}_{\left(\mathrm{NO}_{3}{ }^{-}\right)}\right.$ caused a significant increase in the level of N-nitroso compounds (NOCs) in the urine, measured as ATNC (Apparent Total Nitrosamine Content) after one day and in the next seven days. Based on the data obtained, it was found that vitamin $\mathrm{C}$ supplementation was able to inhibit the excretion of $\mathrm{N}$-nitrosamine compounds (NOCs) after consuming one dose of beetroot juice, but not for a longer period. The authors of the study concluded that caution should be exercised with long-term use of beetroot juice as an intervention to support exercise capacity, and signaled the need for more extensive research to rule out possible long-term adverse health effects (Berends et al., 2019).

The Australian Institute of Sport (AIS) points out the adverse health effects of consuming beetroot juice (especially in higher doses and in concentrated form) in the form of mild gastro-intestinal complaints, and therefore recommends that this nutritional intervention be checked by competitors during the preparation period, and not immediately before or during the competition. AIS also indicates the possible occurrence of temporary pink discoloration of the urine and stools, which in turn is a completely harmless side effect (AIS, 2020).

Although there is insufficient evidence confirming the harmfulness of consuming high doses of nitrates $\left(\mathrm{NO}_{3}{ }^{-}\right)$ with beetroot juice, numerous epidemiological studies can be found in the literature on the subject, analyzing the possible risks to human health related to the consumption of nitrates $\left(\mathrm{NO}_{3}^{-}\right)$and nitrites $\left(\mathrm{NO}_{2}^{-}\right)$along with other foods that are rich in this compound.

Studies assessing the impact of consuming red or processed meat with a high content of nitrates $\left(\mathrm{NO}_{3}{ }^{-}\right)$and nitrites $\left(\mathrm{NO}_{2}^{-}\right)$have shown that its consumption causes the endogenous formation of $\mathrm{N}$-nitroso compounds (NOCs) (Habermeyer et al., 2015; Hebels et al., al., 2012; Hughes, Cross, Pollock, Bingham, 2001; Linseisen et al., 2006). Moreover, the results of prospective cohort studies show an association between red meat consumption and an increased risk of colon (Cross et al., 2011), stomach (Tannenbaum, Correa, 1985) and bladder cancer (Mirvish, 1995).

It is also worth mentioning the increased risk of methaemoglobinaemia with the use of too high doses of nitrite salts (Lundberg, Larsen, Weitzberg, 2011).

Scientists from the World Cancer Research Fund and the American Institute for Cancer Research (2018) observed that the supply of nitrates $\left(\mathrm{NO}_{3}^{-}\right)$in the form of vegetables and fruits correlated with a lower risk of cancer development, which is probably the result of the high content of bioactive compounds in in particular the antioxidants of the above-mentioned food groups. It is also believed that vitamin $C$ present in vegetables is able to inhibit the formation of $\mathrm{N}$-nitroso compounds (NOCs) by reducing $2 \mathrm{HNO}_{2}$ to nitric oxide (NO), while itself being oxidized to dehydroascorbic acid (World Health Organization [WHO], International Agency for Research on Cancer [IARC], 2010). Bahadoran, Mirmiran, kabir, Azizi, Ghasemi (2017) also pointed out that it is unlikely that the acceptable daily intake of nitrates (0.3-7 mg/kg body weight/day) will be exceeded by consuming vegetables and fruits, unless they are consumed daily in concentrated and extremely high doses. 
Taking into account the above data, consumption of beetroot juice containing a high content of nitrates may pose a potential threat to human health, mainly due to the formation of N-nitroso compounds (NOCs). However, it is important to emphasize the beneficial role of bioactive substances contained in fruits and vegetables, including beetroot juice, which may, in turn, positively affect the reduction of the risk of cancer development. However, the above issue requires further research (Zamani et al., 2021).

\section{Variability of the ergogenic effects of the supply of nitrates $\left(\mathrm{NO}_{3}{ }^{-}\right)$along with beetroot juice}

Due to the controversy surrounding the potential effectiveness of a nutritional intervention such as nitrate $\left(\mathrm{NO}_{3}{ }^{-}\right)$supply along with diet, and more specifically with beetroot juice, researchers undertook a study to isolate the factors influencing the variability of ergogenic effects. It has been proven that it can be influenced by several factors i.e. the level of aerobic capacity of the athletes, the time of use, and the proposed nitrate $\left(\mathrm{NO}_{3}{ }^{-}\right)$dose, the interindividual variability in pharmacodynamics (Wylie et al., 2013; Wylie et al., 2016), gender (Wickham, Spriet, 2019), and environmental factors (Shannon et al., 2017). Furthermore, ergogenic potential may be dependent on the oral microbiome, which is responsible for the reduction of nitrate $\left(\mathrm{NO}_{3}^{-}\right)$to nitrite $\left(\mathrm{NO}_{2}^{-}\right)$, and which is shaped by many oral substances such as antibiotics, chewing gum, or antibacterial mouthwashes (Govoni, Jansson, Weitzberg, Lundberg, 2008; Qu et al., 2016).

\section{Conclusion}

In conclusion, although there are conflicting data, it appears that the use of beetroot juice rich in inorganic nitrate $\left(\mathrm{NO}_{3}{ }^{-}\right)$may be an effective nutritional strategy in improving exercise performance, especially in recreational exercisers. Among competitive athletes, there is a need for further research to determine an appropriately higher dose or timing of beetroot juice supply to achieve the desired effect of increased exercise capacity.

There is scientific evidence demonstrating the ergogenic effect of beetroot juice intake in both endurance and intermittent high intensity start-stop exercise. However, more detailed studies analyzing the effect of dietary nitrate $\left(\mathrm{NO}_{3}{ }^{-}\right)$supply on anaerobic exercise - especially high volume resistance training - are needed. Further research is also needed to elucidate the effects of specific factors on the variability of ergogenic effects after beetroot juice consumption, which may be most relevant to the effectiveness of this nutritional intervention. In addition, the impact of an extended period of nitrate $\left(\mathrm{NO}_{3}\right)$ delivery with food beyond the relatively short period that the scientific data present (i.e., up to 15 days) needs to be evaluated to determine whether stronger ergogenic effects can be observed with a longer duration of beetroot juice application, and thus, an in-depth investigation of the long-term safety profile of increased nitrate $\left(\mathrm{NO}_{3}{ }^{-}\right)$delivery, in this case in the form of beetroot juice, should also be considered.

\section{Reférenences}

Ahluwalia, A., Gladwin, M., Coleman, G.D., Hord, N., Howard, G., Kim-Shapiro, D.B., Lajous, M., Larsen, F.J., Lefer, D.J., McClure, L.A., Nolan, B.T., Pluta, R., Schechter, A., Wang, Ch.-Y., Ward, M.H., Harman, J.L. (2016). Dietary nitrate and the epidemiology of cardiovascular disease: report from a National Heart, Lung, and Blood Institute Workshop. Journal of the American Heart Association, 5 (7), e003402. DOI: 10.1161/JAHA.116.003402.

Allen, J.D., Stabler, T., Kenjale, A., Ham, K.L., Robbins, J.L., Duscha, B.D., Dobrosielski, A., Annex, B.H. (2010). Plasma nitrite flux predicts exercise performance in peripheral arterial disease after 3 months of exercise training. Free Radical Biology \& Medicine, 49 (6), 1138-1144. DOI: 10.1016/j.freeradbiomed.2010.06.033.

Australian Institute of Sport (2020). Retrieved from: https://www.ais.gov.au/nutrition/supplements\#group_a (20.02.2021). 
Bahadoran, Z., Mirmiran, P., Kabir, A., Azizi, F., Ghasemi, A. (2017). The nitrate - independent blood pressure - lowering effect of beetroot juice: a systematic review and meta - analysis. Advances in Nutrition, 8 (6), 830-838. DOI: 10.3945/an.117.016717.

Bailey, S.J., Winyard, P., Vanhatalo, A., Blackwell, J.R., Dimenna, F.J., Wilkerson, D.P., Tarr, J., Benjamin, N., Jones, A.M., (2009). Dietary nitrate supplementation reduces the 02 cost of low - intensity exercise and enhances tolerance to high - intensity exercise in humans. Journal of Applied Physiology, 107 (4), 1144-55. DOI: 10.1152/japplphysiol.00722.2009.

Belval, L.N., Hosokawa, Y., Casa, D.J., Adams, W.M., Armstrong, L.E., Baker, L.B., Burke, L., Cheuvront, S., Chiampas, G., Gonzalez-Alonso, J., Huggins, R.A., Kavouras, S.A., Lee, E.C., McDermott, B.P., Miller, K., Schlader, Z., Sims, S., Stearns, R.L., Troyanos, Ch., Wingo, J., (2019). Practical Hydration Solutions for Sports. Nutrients, 11 (7), 1550. DOI:10.3390/nu11071550.

Berends, J.E., van den Berg, L.M.M., Guggeis, M.A., Henckens, N.F.T., Hossein, I.J., Joode, M.E.J.R., Zamani, H., van Pelt, K.A.A.J., Beelen, N.A., Kuhnle, G.G., de Kok, T.M.C.M., van Breda, S.G.J. (2019). Consumption of nitrate - rich beetroot juice with or without vitamin $\mathrm{C}$ supplementation increases the excretion of urinary nitrate, nitrite, and $\mathrm{N}$-nitroso compounds in humans. International Journal of Molecular Sciences, 20 (9), 2277-2292. DOI: 10.3390/ijms20092277.

Brown, G.C., Cooper, C.E. (1994). Nanomolar concentrations of nitric oxide reversibly inhibit synaptosomal respiration by competing with oxygen at cytochrome oxidase. FEBS Letters, 356 (2-3), 295-298. DOI: 10.1016/0014-5793(94)01290-3.

Campbell, S.C., Wisniewski, J. (2017). Nutritional Recommendations for Athletes. W: Nutrtion in the Prevention and Treatment of Disease (255-271). Elsevier. DOI: 10.1016/B978-0-12-802928-2.00013-8.

Cermak, N.M., Res, P., Stinkens, R., Lundberg, J.O., Gibala, M.J., van Loon, L.J.C. (2012). No improvement in endurance performance after a single dose of beetroot juice. International Journal od Sport Nutrition and Exercise Metabolism, 22 (6), 470-8. DOI: 10.1123/ijsnem.22.6.470.

Clements, W.T., Lee, S.R., Bloomer, R.J. (2014). Nitrate Ingestion: A Review of the Health and Physical Performance Effects. Nutrients, 6 (11), 5224-5264. DOI: 10.3390/nu6115224.

Clifford, T., Howaston, G., West, D.J., Stevenson, E.J. (2017). Beetroot juice is more beneficial than sodium nitrate for attenuating muscle pain after strenuous eccentric - bias exercise. Applied Physiology, Nutirtion, and Metabolism, 42 (11), 1185-1191. DOI: 10.1139/apnm-2017-0238.

Cross, A.J., Freedman, N.D., Ren, J., Ward, M.H., Hollenbeck, A.R., Schatzkin, A., Sinha, R., Abnet, Ch.C. (2010). Meat consumption and risk of esophageal and cancer in a large prospecitve study. The American Journal of Gastroenterology, 106 (3), $432-442$. DOI: 10.1038/ajg.2010.415.

Daab, W., Bouzid, M.A., Lajri, M., Bouchiba, M., Saafi, M.A., Rebai, H. (2020). Chronic Beetroot Juice Supplementation Accelerates Recovery Kinetics following Simulated Match Play in Soccer Players. Journal of the American College of Nutrition, 40 (1), 61-69. DOI: $10.1080 / 07315724.2020 .1735571$.

de Castro, F.T., de Assis, M.F., Figueiredo, D.H., Machado, F.A. (2019). Effect of beetroot juice supplementation on 10-km performance in recreational runners., Applied Physiology, Nutrition, and Metabolism, 44 (1), 90-94. DOI: 10.1139/apnm-2018-0277.

Dejam, A., Hunter, C., Schechter, A., Gladwin, M. (2004). Emerging role of nitrite in human biology. Blood Cells, Molecules and Diseases, 32 (3), 423-9. DOI: 10.1016/j.bcmd.2004.02.002.

DeMartino, A.W., Kim-Shapiro, D.B., Patel, P.R., Gladwin, M.T. (2019). Nitrite and nitrate chemical biology and signalling. British Journal of Pharmacology, 176 (2), 228-245. DOI: 10.1111/bph.14484.

Dominguez, R., Cuenca, E., Mate-Munoz, J.L., Garcia-Fernandez, P., Serra-Paya, N., Lozano-Estevan, M.C., Herreros, P.V., Garnacho-Castano, M.V. (2017). Effects of Beetroot Juice Supplementation on Cardiorespiratory Endurance in Athletes. A Systematic Review. Nutrients, 9 (1), 43. DOI: 10.3390/nu9010043.

Dominguez, R., Mate-Munoz, J.L., Cuenca, E., Garcia-Fernandez, P., Mata-Ordonez, F., Lozano-Estevan, M.C., Veiga-Herreros, P., da Silva, S.F., Garnacgo-Castano, M.V. (2018). Effects of beetroot juice supplementation on intermittent high-intensity exercise efforts. Journal of the International Society of Sports Nutrition, 15 (2). DOI 10.1186/s12970-017-0204-9.

Ferguson, S.K., Hirai, D.M., Copp, S.W., Holdsworth, C.T., Allen, J.D., Jones, A.M., Musch, T.I., Poole, D.C. (2013). Impact of dietary nitrate supplementation via beetroot juice on exercising muscle vascular control in rats. The Journal of Physiology, 591 (2), 547-557. DOI: 10.1113/jphysiol.2012.243121.

Fernandez-Elias, V.E., Courel-Ibanez, J., Perez-Lopez, A., Jodra, P., Moreno-Perez, V., Del Coso, J., Lopez-Samanes, A.L. (2020). Acute Beetroot Juice Supplementation Does Not Improve Match - Play Activity in Professional Tennis Players. Journal of the American College of Nutrition, 12 (1), 1-8. DOI: 10.1080/07315724.2020.1835585.

Flores, A.V., Gomez, C.M., Estrada-Catrillion, M., Smitaman, E., Pathria, M.N. (2018). MR Imaging of Muscle Trauma: Antatomy, Biomechanics, Pathophysiology and Imaging Appearance. Radiographics, 38 (1), 124-148. DOI: 10.1148/rg.2018170072. 
Flueck, J.L., Bogdanova, A., Mettler, S., Perret, C. (2016). Is beetroot juice more effective than sodium nitrate? The effects of equimolar nitrate dosages of nitrate - rich beetroot juice and sodium nitrate on oxygen consumption during exercise. Applied Physiology, Nutirtion, and Metabolism, 41 (4), 421-429. DOI: 10.1139/apnm-2015-0458.

Furchgott, R., Jothianandan, D. (1991). Endothelium-dependent and - independent vasodilation involving cyclic GMP: relaxation induced by nitric oxide, carbon monoxide and light. Blood Vessels, 28 (1-3), 52-61. DOI: 10.1159/000158843.

Garnacho-Castano, M.V., Palau-Salva, G., Cuenca, E., Munoz-Gonzalez, A., Garcia-Fernandez, P., Lozano-Estevan, M., Veiga-Herreros P., Mate - Munoz, J.L., Dominguez, R. (2018). Effects of a single dose of beetroot juice on cycling time trial performance at ventilatory threholds intensity in male triathletes. Journal of the International Society of Sports Nutrition, 15 (49). DOI: 10.1186/ s12970-018-0255-6.

Govoni, M., Jansson, E.A., Weitzberg, E., Lundberg, J.O. (2008). The increase in plasma nitrite after a dietary nitrate load is markedly attenuated by an antibacterial mouthwash. Nitric Oxide, 19 (4), 333-7. DOI: 10.1016/j.niox.2008.08.003.

Habermeyer, M., Roth, A., Guth, S., Diel, P., Engel, K.H., Epe, B., Furts, P., Heinz, V., Humpf H.-U., Joost H.-G., Knorr, D., de Kok, T., Kulling, S., Lampen, A., Marko, D., Rechkemmer, G., Rietjens, I., Stadler, R.H., Vieths, S., Vogel, R., Steinberg, P., Eisenbrand, G. (2015). Nitrate and nitrite in the diet: how to asses their benefit and risk for human health. Molecular Nutrition \& Food Research, 59 (1), 106-128. DOI: 10.1002/mnfr.201400286.

Hebels, D.G.A.J., Sveje, K.M., de Kok, M.C., van Herwijnen, M.H.M., Kuhnle, G.G.C., Engels, L.G.J.B., Vleugels-Simon, C.B.E.M., Mares, W.G.N., Pierik, M., Masclee A.A.M., Kleinjans, J.C.S., de Kok, T.M.C.M. (2012). Red meat intake - induced increases in fecal water genotoxicity correlate with pro - carcinogenic gene expression changes in the human colon. Food and Chemical Toxicology, 50 (2), 95-103. DOI: 10.1016/j.fct.2011.10.038.

Hernandez, A., Schiffer, T.A., Ivarsson, N., Cheng, A.J., Bruton, J.D., Lundberg, J.O., Weitzberg, E., Westerblad, H. (2012). Dietary nitrate increases tetanic [Ca2+]i and contractile force in mouse fast-twitch muscle. The Journal of Physiology, 590 (15), 35753583. DOI: 10.1113/jphysiol.2012.232777.

Hinkle, P.C. (2005). P/O ratios of mitochondrial oxidative phosphorylation. Biochimica et Biophysica Acta, 1706 (1-2), 1-11. DOI: 10.1016/j.bbabio.2004.09.004.

Hord, N.G., Tang, Y., Bryan, N.S. (2009). Food sources of nitrates and nitrites: the physiologic context for potential helath benefits. The American Journal of Clinical Nutrition, 90 (1), 1-10. DOI: 10.3945/ajcn.2008.27131.

Hughes, R., Cross, A.J., Pollock, J.R., Bingham, S. (2001). Dose - dependent effect of dietary meat on endogenous colonic N-nitrosation. Carcinogenesis, 22 (1), 199-202. DOI: 10.1093/carcin/22.1.199.

Hurst, P., Saunders, S., Coleman, D. (2020). No differences between beetroot juice and placebo on competitive 5-km running performance: a double - blind, placebo - controlled trial. International Journal of Sport Nutrition and Exercise Metabolism, 30 (4), 295-300. DOI: 10.1123/ijsnem.2020-0034.

Ignarro, L.J., Fukuto, J.M., Griscavage, J.M., Rogers, N.E., Byrns, R.E. (1993). Oxidation of nitric oxide in aqueous solution to nitrite but not nitrate: comparison with enzymatically formed nitric oxide from L-arginine. Proceedings of the National Academy of Sciences, 90 (17), 8103-8107. DOI: 10.1073/pnas.90.17.8103.

Jensen, L., Bangsbo, J., Hellsten, Y. (2004). Effect oh high intensity training on capillarization and presence of angiogenic factors in human skeletal muscle. The Journal of Physiology, 1 (557), 571-582. DOI: 10.1113/jphysiol.2003.057711.

Jeukendrup, A.E (2017). Periodized Nutrition for Athletes. Sports Medicine, 47 (1), 51-63. DOI: 10.1007/s40279-017-0694-2.

Jones, A.M. Vanhatalo, A., Seals, D.R., Rossman, M.J., Piknova, B., Jonvik, K.L. (2021). Dietary Nitrate and Nitric Oxide Metabolism: Mouth, Circulation, Skeletal Muscle, and Exercise Performance. Medicine \& Science in Sports \& Excercise, 53 (2), $280-294$. DOI: 10.1249/MSS.0000000000002470.

Larsen, F.J., Schiffer, T.A., Borniquel, S., Sahlin, K., Ekblom, B., Lundberg, J.O., Weitzberg, E. (2011). Dietary inorganic nitrate improves mitochondrial efficiency in humans. Cell Metabolism, 13 (2), 149-159. DOI: 10.1016/j.cmet.2011.01.004.

Larsen, F.J., Schiffer, T.A., Weitzberg, E., Lundberg, J.O. (2012). Regulation of mitochondrial function and energetics by reactive nitrogen oxides. Free Radical Biology \& Medicine, 53 (10), 1919-1928. DOI: 10.1016/j.freeradbiomed.2012.08.580.

Larsen, F.J., Weitzberg, E., Lundberg, J.O., Ekblom, B. (2007). Effects of dietary nitrate on oxygen cost during exercise. Acta Physiologica, 191 (1), 59-66. DOI: 10.1111/j.1748-1716.2007.01713.x.

Linseisen, J., Rohrmann, S., Norat, T., Gonzalez, C.A., Ireaeta, M.D., Gomez, P.M., Chirlaque, M.-D., Pozo, B.G., Ardanaz, E., Mattisson, I., Pettersson, U., Palmqvist, R., van Guelpen, B., Bingham, S.A., McTaggart, A., Spencer, E.A., Overvad K., Tjonneland, A., Stripp, C., Clavel-Chapelon, F., Kesse, E., Boeing, H., Klipstein-Grobusch, K., Trichopoulou, A., Vasilopoulou, E., Bellos, G., Pala, V., Masala, G., Tumino, R., Sacerdote, C., del Pezzo, M., Bueno-de-Mesquita, H.B., Ocke, M.C., Peeters, P.H.M., Engest, D., Skeie, G., Slimani, N., Riboli, E. (2006). Dietary intake of different types and characteristics of processed 
meat which might be associated with cancer risk - results from the 24-hour diet recalls in the European Prospecitve Investigation into Cancer and Nutrition (EPIC). Public Health Nutrtion, 9 (4), 449-464. DOI: 10.1079/phn2005861.

Logan-Sprenger, H.M., Logan, S.L. (2016). Acute dose of beet root juice does not improve endurance performance in elite triathletes. Journal of Nutrition Science Research, 1 (2), 108. DOI: 10.4172/2473-6449.1000108.

Lopez-Samanes, A., Parra, A.G., Moreno-Perez, V., Courel-Ibanez, J. (2020). Does Acute Beetroot Juice Supplementation Improve Neuromuscular Performance and Match Activity in Young Basketball Players? A Randomized, Placebo - Controlled Study. Nutrients, 12 (1), 188. DOI: 10.3390/nu12010188.

Lundberg, J.O., Carlström, M., Larsen, F.J., Weitzberg, E. (2011). Roles of dietary inorganic nitrate in cardiovascular health and disease. Cardiovascular Research, 89 (3), 525-532. DOI: 10.1093/cvr/cvq325.

Lundberg, J.O., Larsen, F.J., Weitzberg, E. (2011). Supplementation with nitrate and nitrite salts in exercise: a word of caution. Journal of Apllied Physiology, 111 (2), 616-617. DOI: 10.1152/japplphysiol.00521.2011.

Lundberg, J.O., Weitzberg, E., Gladwin, M.T. (2008). The nitrate-nitrite-nitric oxide pathway in physiology and therapeutics. Nature Reviews Drug Discovery, 7 (2), 156-67. DOI: 10.1038/nrd2466.

Maughan, R.J., Burke, L.M., Dvorak, J., Larson-Meyer, D.E., Peeling, P., Phillips, S.M., Rawson, E.S., Walsh, N.P., Garthe, I., Geyer, H., Meeusen, R., van Loon, L.J.C., Shirreffs, S.M., Spriet L.L., Stuart, M., Vernec, A., Currell, K., Ali, V.M., Budgett, R.G.M., Ljungqvist, A., Mountjoy, M., Pitsiladis, Y.P., Soligard, T., Erdener, U., Engebretsen, L. (2018). IOC consensus statement: dietary supplements and the high - performance athlete. British Journal of Sports Medicine, 52 (7), 439-455. DOI: 10.1136/ bjsports-2018-099027.

McConell, G.K., Bradley, S.J., Stephens, T.J., Canny, B.J., Kingwell, B.A., Lee-Young, R.S. (2007). Skeletal muscle nNOS mu protein content is increased by exercise training in humans. American Journal of Physiology - Regulatory, Integrative and Comparative Physiology, 293 (2), R821-8. DOI: 10.1152/ajpregu.00796.2006.

Mirvish, S.S. (1995). Role of N-nitroso compounds (NOC) and N-nitrosation in etiology og gastric, esophageal, nasopharyngeal and bladder cancer and contribution to cancer of known exposures to NOC. Cancer Letters, 93 (1), 17-48. DOI: 10.1016/0304-3835(95)03786-V.

Murphy, M., Eliot, K., Heuertz, R.M., Weiss, E. (2012). Whole beetroot consumption acutely improves running performance. Journal of the Academy of Nutrition and Dietetics, 112 (4), 548-552. DOI: 10.1016/j.jand.2011.12.002.

Nyakayiru, J., Jonvik, K.L., Trommelen, J., Pinckaers, P.J.M., Senden, J.M., van Loon, L.J.C., Verdijk, L.B. (2017). Beetroot Juice Supplementation Improves High-Intensity Intermittent Type Excercise Performance in Trained Soccer Players, Nutrients, 9 (3), 314. DOI: 10.3390/nu9030314.

Paton, C.D., Hopkins, W.G. (2006). Variation in performance of elite cyclists from race to race. European Journal of Sport Science, 6 (1), 25-31. DOI: 10.1080/17461390500422796.

Peacock, O., Tjonna, A.E., James, P., Wisloff, U., Welde, B., Bohlke, N., Smith, A., Stokes, K., Cook, Ch., Sandbakk, O. (2012). Dietary nitrate does not enhance running performance in elite cross - country skiers. Medicine \& Science in Sports \& Exercise, 44 (11), 2213-2219. DOI: 10.1249/MSS.0b013e3182640f48.

Piknova, B., Park, J.W., Kwan, J., Lam, K., Schechter, A.N. (2016). Nitrate as a source of nitrite and nitric oxide during exercise hyperemia in rat skeletal muscle. Nitric Oxide, 55, 54-61. DOI: 10.1016/j.niox.2016.03.005.

Piknova, B., Park, J.W., Swanson, K.M., Dey, S., Noguchi, C.T., Schechter, A.N. (2015). Skeletal muscle as an endogenous nitrate reservoir. Nitric Oxide, 47, 10-16. DOI: 10.1016/j.niox.2015.02.145.

Pinna, M., Roberto, S., Milia, R., Maronquiu, E., Olla, S., Loi, A., Migliaccio, G.M., Padulo, J., Orlandi, C., Tocco, F., Concu, A., Crisafulli, A. (2014). Effect of beetroot juice supplementation on aerobic response during swimming. Nutrients, 6 (2), 605-15. DOI: 10.3390/nu6020605.

Poveda, J.J., Riestra, A., Salas, E., Cagigas, M.L., Lopez-Somoza, C., Amado, J.A., Berrazueta, J.R. (1997). Contribution of nitric oxide to exercise - induced changes in healthy volunteers: effects of acute exercise and long - term physical training. European Journal of Clinical Investigation, 27 (11), 967-971. DOI: 10.1046/j.1365-2362.1997.2220763.x.

Puype, J., Ramaekers, M., Thienen, R., Deldicque, L., Hespel, P. (2015). No effect of dietary nitrate supplementation on endurance training in hypoxia. Scandinavian Journal of Medicine \& Science in Sports, 25 (2), 234-241. DOI: 10.1111/sms.12199.

Qu, X.M., Wu, Z.F., Pang, B.X., Jin, L.Y., Qin, L.Z., Wang, S.L. (2016). From Nitrate to Nitric Oxide: The role od salivary glands and oral bacteria. Journal of Dental Research, 95 (13), 1452-1456. DOI: 10.1177/0022034516673019.

Ranchal-Sanchez, A., Diaz-Bernier, V.M., De La Florida-Villagran, C.A., Llorente-Cantarero, F.J., Campos-Perez, J., Jurado-Castro, J.M. (2020). Accute Effects of Beetroot Juice Supplements on Resistance Training: A randomized Double - Blind Crossover. Nutrients, 12 (7), 1912. DOI: 10.3390/nu12071912. 
Rojas-Valverde, D., Montoya-Rodriquez, J., Azofeifa-Mora, Ch., Sanchez-Urena, B. (2020). Effectiveness of beetroot juice derived nitrates supplementation on fatigue resistance during repeated - sprints: a systematic review. Critical Reveiws in Food Science and Nutrition, 25, 1-12. DOI: 10.1080/10408398.2020.1798351.

Rokkendal-Lausch, T., Franch, J., Poulsen, M.K., Thomsen, L.P,. Weitzberg, E., Kamavuako, E.N., Karbing, D.S., Larsen, R.G. (2019). Chronic high - dose beetroot juice supplementation improves time trial performance of well - trained cyclists in normoxia and hypoxia. Nitric Oxide, 1 (85), 44-52. DOI: 10.1016/j.niox.2019.01.011.

San Juan, A.F., Dominguez, R., Lago-Rodriguez, A., Montoya, J.J., Tan, R., Bailey, S.J. (2020). Effects of Dietary Nitrate Supplementation on Weightlifting Exercise Performance in Healthy Adults: A Systematic Reveiw, Nutrients, 12 (8), 2227. DOI: 10/3390/nu12082227.

Santamaria, P. (2005). Nitrate in vegetables: toxicity, content, intake and EC regulation. Journal of the Science of Food and Agriculture, 86 (1), 10-17. DOI: 10.1002/jsfa.2351.

Senefeld, J.W., Wiggins, Ch.C., Regimbal, E.J., Dominelli, P.B., Baker, S.E., Joyner, M.J. (2020). Ergogenic effect of Nitrate Supplementation: A Systematic Review and Meta - analysis. Medicine and Science in Sports and Excercise, 52 (10), $2250-2261$. DOI: $10.1249 /$ MSS.0000000000002363.

Shannon, O.M., McGawley, K., Nyback, L., Duckworth, L., Barlow, M.J., Woods, D., Siervo, M., O'Hara, J.P. (2017). "Beet-ing” the mountain: a review of the physiological and performance effects of dietary nitrate supplementation at simulated and terrestrial altitude. Sports Medicine, 47 (11), 2155-2169.

Tannenbaum, S.R., Correa, P. (1985). Nitrate and gastric cancer risks. Nature, 317, 675-676. DOI: 10.1038/317675b0.

Tannenbaum, S.R., Sinskey, A.J., Weisman, M., Bishop, W. (1974). Nitrite in human saliva. Its possible realtionship to nitrosamine formation. Journal of the National Cancer Institute, 53 (1), 79-84.

Thomas, D. T., Erdman, K.A., Burke, L.M. (2016). Position of the Academy of Nutrition and Dietetics, Dietitians of Canada and the American College of Sports Medicine. Nutrition and athletic performance. Journal of the Academy of Nutrition and Dietetics, 116 (3), 501-528. DOI: 10.1016/j.jand.2015.12.006.

Thompson, Ch., Vanhatalo, A., Jell, H., Fulford, J. (2016). Dietary nitrate supplementation improves sprint and high - intensity intermittent running performance, Nitric Oxide, 43 (8), 1-29. DOI: 10.1016/j.niox.2016.10.006.

Vitale, K., Gatzin, A. (2019). Nutrition and Supplement Update for the Endurance Athlete. Review and Recommendations, Nutrients, 11 (6), 1289. DOI: 10.3390/nu11061289.

Ward, M.H., Jones, R.R., Brender, J.D., de Kok, T.M., Weyer, P.J., Nolan, B.T., Villanueva, C.M., van Breda, S.G. (2018). Drinking water nitrate and human health: an update review. Journal of Environmental and Public Health, 15 (7), 1557. DOI: 10.3390/ ijerph15071557.

Wickham, K.A., Spriet, L.L. (2019). No longer beeting around the bush: a review of potential sex differences with dietary nitrate supplementation. Applied Physiology, Nutrition, and Metabolism, 44 (9), 915-924. DOI: 10.1139/apnm-2019-0063.

Wilkerson, D.P., Hayward, G.M., Bailey, S.J., Vanhatalo, A., Blackwell, J.R., Jones, A.M. (2012). Influence of acute dietary nitrate supplementation on 50 mile time trial performance in well - trained cyclist. European Journal of Applied Physiology, 112 (12), 4127-4134. DOI: 10.1007/s00421-012-2397-6.

World Cancer Research Fund (WCRF), American Institute for Cancer Research (AICR) (2018/15.07.2021). Diet, nutrition, physical activity and cancer: a global perspective. Continuous update project expert report 2018. Retrieved from: https://www.wcrf.org/ diet-and-cancer.

World Health Organization (WHO), International Agency for Research on Cancer (IARC) (2010). IARC monographs on the evaluation of carcinogenic risks to humans. Ingested Nitrate and Nitrite, and Cyanobacterial Peptide Toxins. Lyon, France.

Wylie, L.J., Kelly, J., Bailey, S.J. Blackwell, J.R., Skiba, P.F., Winyard, P.G., Jeukendrup, A.E., Vanhatalo, A., Jones, A.M. (2013). Beetroot juice and exercise: pharmacodynamic and dose-response relationships. Journal of Applied Physiology, 115 (3), 325336. DOI: 10.1152/japplphysiol.00372.2013.

Wylie, L.J., Ortiz de Zevallos, J., Isidore, T., Nyman, L., Vanhatalo, A., Bailey, S.J., Jones, A.M. (2016). Dose-dependent effects of dietary nitrate on the oxygen cost of moderate-intensity exercise: acute vs. chronic supplementation. Nitric Oxide, 57, 30-39. DOI: 10.1016/j.niox.2016.04.004.

Zamani, H., de Joode, M.E.J.R., Hossein, I.J., Henckens, N.F.T., Guggeis, M.A., Berends, J.E., Berends, J.E., de Kok T.M.C.M., van Breda, S.G.J. (2021). The benefits and risks of betroot juice consumption: a systematic review. Critical Reviews in Food Science and Nutrition, 61 (5), 788-804. DOI: 10.1080/10408398.2020.1746629.

Cite this anticle aS: Kurowska, K., Antosik, K., Kobylińska, M., Decyk, A. (2021). Beetroot Juice - Legal Doping for Athletes? Central European Journal of Sport Sciences and Medicine, 3 (35), 57-70. DOI: 10.18276/cej.2021.3-06. 